\title{
Lack of Knowledge and Negative Beliefs about Colorectal Cancer: FOBT and Dietary Risk Factors in Makkah, KSA
}

\author{
Hassan M. Bukhari \\ Department of Clinical Nutrition, Faculty of Applied Medical Sciences, Umm Al-Qura University, Makkah, Saudi Arabia
}

Copyright $\bigcirc 2018$ by authors, all rights reserved. Authors agree that this article remains permanently open access under the terms of the Creative Commons Attribution License 4.0 International License

\begin{abstract}
Colorectal cancer (CRC) is the third most common disease in males and second in females. A negative attitude about information such as prevalence, screening tests and poor dietary factors might increase risk. The aim was to measure knowledge and beliefs about screening test and some dietary factors. A cross-sectional study with 2564 participants was done. A validated questionnaire was used. SPSS (version 16) was used. The majority (60-80\%) did not have knowledge about the risk of CRC. Only $25 \%$ knew it is widely occurring, about $22 \%$ knew it is higher in western society. Only about 5\% men and $13 \%$ women realized the correct order to have CRC for their gender. Of total, $21 \%$ recognized that it is most common in men, yet, men scored better than women $(23 \%$ vs $18 \%$ ). Approximately $12 \%$ vs $17 \%$, of men and women resp, have chosen FOBT as the screening test for CRC. Both genders understand the role of high fiber to reduce CRC (54\% vs63\% men and women resp). In comparison, only about $10-13 \%$ of both genders do not believe that nor does cooking type neither obesity affect CRC risk negatively. More health programs to increase the awareness and changing wrong beliefs should be done.
\end{abstract}

Keywords Colorectal Cancer Risk, Awareness, Makkah, High Fiber, Obesity

\section{Introduction}

One of the leading reasons of mortality globally are cancers, about 8.2 million persons die in 2012 for several types of cancers [1]. The most common killer cancers around the world were lung, liver, stomach, colorectal and breast cancers [2]. About $70 \%$ of all tumors deaths occurred according to income level were in low- and middle-income countries, and these figures are getting higher [3]. Deaths from the different types of cancers internationally are anticipated to rise over 13.1 million in 2030 [4].

In 2012, CRC was the fourth in rank of death worldwide out of the major six types of cancers [1]. Recently, Arnold [3] reported that it is expected to have a higher burden with $60 \%$ and more than 2 million cases to be diagnosed as CRC patients. The death could be as high as 1 million by 2030 . CRC affects both men and women of all racial and ethnic groups, and is most often found in people aged 50 years or older [5]. Across the globe now CRC is the third most common cancer in men and the second in women [6]. Cancer incidence report in Saudi Arabia, Al- Eid [7] and recently Sayed Al-Amin [8] recorded that CRC is, of all ages, the first cancer as incidence for men and the third for the women, and both the incidence and mortality rates are lower in women than in men.

Screening is a procedure for cancer detection at early stages in public who have no symptoms of the disease. Various examinations can be used to screen $\mathrm{CRC}$, one is testing the stool for signs that cancer may be present, the most known is fecal occult blood test (FOBT). The FOBT is easy to perform in small laboratory and did not cause inconvenient to the examined person, yet this test cannot detect the polyps which are been formed in the GIT [9]. In the USA, insignificant number of public contribute to the CRC screening examinations, and the United States Preventive Services Task Force found that the rates for the at higher risk group (adults aged 50 to 75 years) was very low [10]. Public health awareness of cancers is increasingly growing in Saudi Arabia and other countries. However, different global studies proved that the extent of awareness about the early diagnosis of CRC were negative. Harmy [11] run a cross-sectional study in West Malaysia. A total of $1,905(93.8 \%)$ patients responded. Treatment is only sought at late stage by $80 \%$ of the studied sample, as they stated that this might be due to lack of awareness. A minority had done the test for CRC screening (less than 1\%) because they were not worried and feeling uncomfortable or being busy. The study also indicated that lower 
knowledge and negative attitudes for the CRC screening test comes in most patients with moderate risk. Another study done by Taskila [12] reported that $14 \%$ percent of respondents had a negative attitude towards screening. Men, older people, and those with Indian ethnic backgrounds were more likely to have negative attitudes toward screening, whereas people with black Caribbean ethnic, people with multiple symptoms and those reporting abdominal pain, bleeding, and tiredness were more likely to have a positive attitude.

As for the role of diet and dietary factors many studies and reports found that diet in general and specific nutrients can explain up to $50 \%$ of the global incidence of CRC [13]. The conjunction of the American institute for Cancer research (AICR) and the world cancer research fund (WCRF) in 2011 reported that many nutrients like calcium, folate and vitamin D affect cancer. The higher those nutrients in meal consumption the less risk level for CRC observed. Several food items such as dietary fat, red and processed meat and dairy products affect risk of cancer. More consumption of red meat and fatty diet has been associated with increased risk of CRC. On the contrary, the higher consumption of dairy products reduces risk of CRC [14].

Another supportive study to show the effect of diet in CRC (was the switching diet study by Harvard, where 40 African, of which 20 were African American who used to consumed western high fat diet and 20 original African who used to consume high fiber; low fat diet were switched their diet for 2 weeks. At the end of the experiment, colonoscopies were carried out for all. It showed a reduced in inflammation and other factors linked to CRC in the African American who eat healthy original African diet. In contrast, the original Africans who start to consume western fatty diet with low fiber have shown more signs of inflammations that related to increased risk of CRC. Although this study had used a small sample size, yet the strength is that they used the same people with diet to be only the different factor. The study explains that role of diet could be due to change on the chemical and bacterial patterns in the GIT, which are well known to their role in increased risk of CRC [15].

A large screening and meta-analysis literature published by Baena and Salinas [16] were they found that the risk of CRC increased $19 \%$ by obesity and influenced by total intake and frequency of red meat. On the contrary, the risk of CRC reduced $25 \%$ if high fiber diet consumed $(20 \mathrm{~g} /$ day fiber) and $26 \%$ if milk consumed by $525 \mathrm{ml} /$ day in men.

In Saudi Arabia and other Arabic countries, there are scares studies on the awareness of CRC and its screening methods. To our knowledge two recent articles have been published with regards to this issue, a study in Riyadh in 2015 conducted in normal adult from the public where a survey run in 1070 adults and asked about knowledge towards CRC using 10questions model to find that about $43 \%$ believe that screening should start at beginning of the symptoms, $20 \%$ indicated the correlation of polyps with risk of CRC, the study found that there is a lower awareness even in the most educated groups towards some issue related to CRC like screening, symptoms and general understanding of these concepts [17].

In 2016, Imran and colleagues [18] in Jeddah conducted a study in university students (525 participants, mostly medical students) from different faculties regarding their knowledge and awareness of CRC using a 28items preused questionnaire. The study found that most of the students aware of CRC and 33\% knew the screening tests, large proportion (84\%) believed that CRC can be treated, they knew and identified some of the important factors can be a risk for CRC like family history, age, infection of the GIT, obesity and lack of exercise by $60 \%$ of respondents. The knowledge of students from medical school is far better than other faculties' students and in general the total knowledge is lower than expected.

However, in Makkah using a large sample of both genders has been not been conducted before to our knowledge. Furthermore, the current study has a comprehensive approach to measure many aspects related to CRC such as awareness, knowledge attitude and screening test with risk factors such as some dietary factors that related to increase of incidence of CRC.

\section{Objectives}

To measure the information, attitude and knowledge about the CRC and its screening methods in Makkah community (Western Province of Saudi Arabia).

To understand the effect of some dietary factors in risk of CRC namely, cooking types, high fiber diet, and obesity

\section{Materials and Methods}

\subsection{Study Design}

A cross sectional study design has been chosen and carried out in Makkah governorate at March 2011 till February 2012 f0r 12 months. Healthy volunteers (male and female) were recruited aged 19 or above from Makkah.

\subsection{Sampling Technique and Size}

A convenience sampling technique has been selected for the easiness to have a large sample. The preferred sample size at the beginning was 3000 participants. At the end of this study in February 2012, a total of 2564 healthy volunteers were participated with about $86 \%$ response rate (Table 1 of sampling tree). The age of the respondents was ranged from 20-74 years old (data not shown here). However, the age group of 60year and above was small (only 16 individuals) thus it was added to the previous 
category (41-60). Exclusion criteria were those who are CRC patients.

\subsection{Survey}

Data was obtained using a structured questionnaire that was divided into: socio-demographic, health, knowledge about the CRC. The knowledge about diagnostic method and dietary factors that are related to increase risk of CRC were also measured. This questionnaire has been constructed according to previous studies in cancer and attitudes [19-21], the $1^{\text {st }}$ version has been given to three reviewers specialized in nutritional and public health field. The comments have been considered and a $2^{\text {nd }}$ version was developed. It has been applied to a pilot sample of 100 people around the university campus at different age groups and asked if they have any unclear questions. The findings then lead to the formation of a $3^{\text {rd }}$ and the final copy, which was used in this study. The data were collected by giving the questionnaire to the volunteers to fill it under the team supervision.

Table 1. Sampling tree

\begin{tabular}{|c|c|}
\hline Sample size wanted & 3000 \\
\hline Sample achieved & 2564 \\
\hline Respond Rate & $(86 \%)$ \\
\hline Male & 1423 \\
& $(56 \%)$ \\
\hline \multirow{2}{*}{ Female } & 1125 \\
& $(44 \%)$ \\
\hline
\end{tabular}

\subsection{Statistical Analysis}

All data collected were tabulated and the statistical analysis was performed using the Statistical Package for Social Sciences (SPSS) version 16. Qualitative data were expressed as percentages, and results are presented as frequencies. For comparing the groups, chi-square test was used. P-value of less than 0.05 was considered statistically significant.

\subsection{Ethical Approval and Research Fund}

This study was accepted by the Ethics Committee of the University of Umm Al-Qura. It was part of a larger research project (Chair) which was the first in Umm Al Qura University funded by Saudi family (shaik Jameel Khogeer).

\section{Results}

Table 2 is for the distribution of the study groups according to their age, educational levels and income are given. In total, male represented (56\%) as compared with female $(44 \%)$. Out of all, $60 \%$ were in age group 20-30 year for both genders. This is followed by $17 \%$ who are between 31-40 year in male group and the group of younger than 20 years for female. There is a trend of increase education in the sample stopped at the graduate level. In addition, approximately $50-60 \%$ of volunteers had a graduate level, followed by about $18-33 \%$ of high school holders.

Moreover, a quarter of all volunteers have a total income less than $1500 \mathrm{SR}$, furthermore, about $21 \%$ have a total income up to $10000 \mathrm{SR}$. the other three categories have some variation according to gender.

Table 3 shows that about the same percentage of people from both genders did not know that colorectal cancer is widespread in the world (63\% vs $68 \%$ of men and women resp). On the other hand, male and female participants who knew that CRC is widespread in the world were $26 \%$ and $23 \%$ respectively, compared to $10 \%$ in total who said no, which is close to the percentage obtained from each group separately. The differences were statistically significant (P value 0.014$)$. Most of the people did not know that there are a higher prevalence of colon cancer in western countries than developing countries ( $71 \%$ ). In fact only $22 \%$ of them believe that it is higher in western countries as compared with developing countries (correct answer). A very small proportion $(8 \%)$ in both genders has a negative understanding (who said no)

Most of people $(75 \%)$ did not know the order of incidence of colorectal cancer in Saudi Arabia for different genders, table 4 . Only $5 \%$ of men put it in the $1^{\text {st }}$ order for men (correct order for men) compared to $2 \%$ of women. In contrast, only $12 \%$ of men put it in the third order for women compared to $13 \%$ of women (correct order for women). However, $7-9 \%$ of all respondents put it in the $2^{\text {nd }}$ order (wrong order). This might explain why only $23 \%$ of men and $18 \%$ of women knew that CRC affect men more than women. Nevertheless, about $10 \%$ in total believe it is not common in men. Seventy percent of all respondents did not know at all about cancer and who been affected most. All differences were statistically significant ( $\mathrm{P}$ value $<$ $0.001)$.

In table 5 when asked about what is the screening test for $\mathrm{CRC}$ in both genders to be significantly different in knowledge and if they are worried to do it, the study found a statistically significant differences between the genders ( $\mathrm{P}$ value $<0.001$ ), where that $80 \%$ of all people do not know FOBT. In contrast, only $12 \%$ men and $17 \%$ women recognized FOBT as early detection method for CRC. If they knew, FOBT, lowest percentage was worried of the inconvenient of the test ( $3 \%$ from both genders). and the highest proportion of respondents was not worried at all (about 97\%).Men were different from women regarding worrying about messiness and dirtiness of FOBT, from both genders up to $45 \%$ do not know if FOBT being missy and dirty. More women categorized as more worried than men $(26 \%$ somewhat worried and 16\%exteremely worried of messiness and dirtiness of FOBT compared to $16 \%$ and $10 \%$ of men respectively).

Table 6 shows the three selected dietary factors and 
increased risk of CRC, with regard to the effect of types of cooking on increasing the risk of the CRC. Approx 60\% and $51 \%$ of women and men (resp) answered that no relation exist (wrong one), followed by up to $38 \%$ who do not know. In comparison, low percentage believes there is a relation $(10 \%)$ for both genders. There is a highly statistical difference between males and females, with women highly unlikely to have knowledge about the relation of cooking types and CRC $(\mathrm{P}<0.001)$.

In this table, the awareness of respondents of the benefit of eating high fiber foods on colon cancer has shown that the majority of sample answered yes there is a benefit (the right answer), with $54 \%$ for male and $64 \%$ for females.

In comparison, about 41 and $33 \%$ of men and women respectively simply do not know. Only small percentage ranging between 5 to $3 \%$ of men and women respectively who believe there is no benefits what so ever (wrong answer). There is a highly statistical difference $(\mathrm{P}<0.001)$ between males and females.

Regarding the link between obesity and increased risk of $\mathrm{CRC}$, when both gender were asked about their knowledge and believe, about half of both genders believe that there is no relation (answered no) which is a wrong answer. Again large proportion does not know at all (43 and 38\% approx) from men and women respectively. Only between 10 to $13 \%$ for male and female groups respectively believe that there is a relationship (correct answer). There is a statistical difference $(\mathrm{P}<0.01)$ between males and females.

\section{Discussion}

The project stem from the fact that CRC was the first cause of death by cancer in men in Saudi Arabia and the third for women. In this study, most of age groups ranging between $20-30$ (60.3\% from total), and the majority of them were holding a graduate level (about 59\% from total). The total income for about quarter of volunteers either is less than 1500 Saudi Riyal (26.1\% from total) or above 10 thousands Riyal.

\subsection{Measure Knowledge Status about the CRC}

In our study, about two thirds of the study population lack the knowledge about the CRC $(65.2 \%$ of the individuals do not know that the CRC is a common disease). The low level of knowledge about CRC among our study population is similar to survey done in Riyadh area by Ravichandran [22] which shows that the knowledge of cancer is poor among the public of 1407 individuals who participated in the study. Another study conducted by Parveze [23] in Al-Madinah Al-Munawara to assesses the knowledge about the causes of GIT cancers of doctors, nurses, and patients suffering from gastrointestinal tract (GIT) cancer and some participants from the general public. It has found that majority of doctors and nurses had good knowledge while the knowledge of patients and general public was low. The Malaysian study (2011) conducted by Harmy and his colleagues [11] indicated that deficiency in knowledge and attitude for CRC among the respondents. This and previous results reflect that the respondents in all these countries including Saudi Arabia had a poor knowledge about CRC regardless to the high incidence of the disease. The low knowledge level might be either explained by limited and infrequent awareness campaign about its magnitude as one of the important killing cancer in the KSA, or that the passed message was misunderstood or forgotten.

Our study shows that most of people do not know about the order of risk or prevalence and incidence of CRC in Saudi Arabia. Only 5\% and 2\% of the male and female answered the correct order in the worldwide and Saudi Arabia, respectively. This lacking of knowledge is much higher than a recent study by Al-Naggar [24]. In Al Anggar study only $5-13 \%$ of the male and female students did not know or heard about CRC.

In contrast, a recent study in nearby city in KSA, applied to university students has shown a positive attitude with about half of the sample heard about CRC compared to $50 \%$ in our study who did not [8].

One reason might come from that Sayed Al-Amin study [8] had been conducted in medical students who could have studied about CRC as a disease during their courses. Another explanation might be due to increase awareness of the public since the current study had been conducted and due to the increase of usage of social media to spread knowledge and health message. Harmy [11] had contributed the lack of knowledge to the limited roles played by the physicians in primary and secondary care facilities were $5 \%$ of the respondents get their knowledge from physicians.

Additionally, only $20.8 \%$ of all selected volunteers in the current study (men and women) answered correctly about the CRC incidence to be higher in males than females. However, female scored worse with $12 \%$ of them think CRC did not affect men more than women. In Iran a study compared knowledge and attitude of university staff and high school teachers (male and female) for CRC attitude and practice to find that the opposite with female teacher whom scored better in knowledge than men, yet female university staff scored worse as in our study compared to men [25].

\subsection{Measure the Knowledge about Screening Method for CRC}

CRC starts with a growth (polyp) that is not cancer. Screening can find and remove growths before they develop into cancer. Usually, there are no early warning signs for this type of cancer, which make screening so important [26].

Screening for CRC has been shown both to detect tumors at earlier stages and to decrease mortality from 
CRC. In the current study FOBT was used as the early screening test compared to blood test (wrong answer). Only $12 \%$ men and $17 \%$ women answer correctly to this question. The rate was very low, additionally the majority do not know at all $(82 \%)$ for both genders. A closer proportion found in the Malaysian study by Harmy [11] where $93 \%$ of the respondents did not know about either FOBT or colonoscopy tests for CRC. A better scoring and recognition was found in an Indonesian study by Murdani [27] with $28 \%$ identifies colonoscopy and $19 \%$ identify FOBT as tests for CRC screening. In contrast, $47 \%$ of the sample of Dolan study [28] out of 377 does not know the test that find CRC. In United States, the rates of recognizing CRC screen test for 2010 have raised to $58.6 \%$ compared to $(20-30 \%)$ in 1997 . Our findings also disappointing, yet, it is better than a recent study for population of Malay, where only $3.2 \%$ heard of FOBT [24].

In Saudi Arabia, Jeddah city, Sayed AlAmin study [8] among university students found a better score with about $23 \%$ knew FOBT as early screening test for CRC. The limited access to the health care system with CRC prevention programs may account for part of low rate of screening among our population as hypothized by Fedewa [29].

Several studies suggest that if respondents do not know FOBT test and how it has been done they became extremely worried of doing it $[11,24]$. In the current study, about $16 \%$ of men and $26 \%$ of women had a somewhat worries about the test. Additionally, up to $16 \%$ of both genders were worried if the test is embarrassing because it might be dirty or messy. These percentages were much higher than the USA study among veterans or experts who does not done screening before, where it found that about $18 \%$ found FOBT test to be messy and about $7 \%$ only believe this test is too embarrassing [28]. In contrast, our findings is close to what has been found in Malaysia study where $62 \%$ think it is embarrassing, $51 \%$ said it might be painful and $52 \%$ of them find it uncomfortable and troublesome [11].

In Sayed-Alamin study [8] in KSA, among university students the barrier in $19 \%$ to do early detection test for $\mathrm{CRC}$ was that it might be embarrassing. About half of a sample from an Al Naggar study [24] in Malay believes that early detecting tests for CRC might be painful like the FOBT $(54 \%)$ or embarrassing like sigmoidscopy $(55 \%)$. This might be due to cultural disapproval and taboo about stool or the screening test procedure.

\subsection{Dietary Risk Factors for CRC}

The dietary factors we asked about in the current study leaning toward poor knowledge and beliefs of the public, and mostly lack of understanding to the relation of these factors to increased risk of CRC.

In general, the population has a negative belief in regards to the effect of cooking on cancers, where only $10 \%$ believed there is a relation compared to 50 and $60 \%$ of men and women resp who do not know the relationship exist. Additionally, about $38 \%$ and $30 \%$ of men and women resp. do not have any information.

Several types of cooking used, some are more common than others, for example, stewing, barbeque, frying and roasting. Consumption of processed food like sausages and luncheons is also a common food items for dinner or breakfast meals [1].

It is well known that red meat consumption being fresh or processed associated with an effect on the colon microbial flora. In mice model that being feed on high fat diet, the data has shown that there is an increased gene expression leading to cancer [30,31].

Several cooking methods have been found to be a culprit and increased risk of CRC including frying, barbequing. In the UK, the cancer research organization found that meat been fried or barbequed or char-grilled would increase the risk of CRC due to increase the formulation of certain carcinogens such as heterocyclic amines and some hydrocarbons, when meat of chicken and fish are fired, frying vegetables producing acrylamide particularly with long meat cooking [32]. Frying in fats or oils at high heat and exposure to air and moistures lead to formation of oxidisable compounds. This is in turn can be harmful to health. Thus, it was recommended to change the frying oil if these compounds reach to level higher than a quarter of total oil weight. The severe effect, if oil has not been changed more frequently, might range from un-digestibility to severe as CVD and cancers development [33].

Sinha [30] suggest that adenoma increased in the colon with more red meat consumptions $(\mathrm{OR}=1.26,95 \% \mathrm{CI})$. The higher consumption of bacon and sausages would increase the risk of colorectal adenoma by 1.14 compared to non-consumers.

It is not only the frying process might pose a risk for increased cancer. It also extended to the types of fatty acids to be eaten, absorbed and stored in the adipose tissue around the body. A recent study found that saturated and monounsaturated fatty acids are highly accumulated in the subcutaneous and visceral fat in colon cancer patients in contrast to controls. However, omega-3 and PUFAs have been shown to decrease this risk, interestingly, they were found to be higher in control subjects [34].

When the current study asked about role of fibre in protection against CRC, a better score was achieved with more than $50 \%$ of the respondents said yes it will protect. The female awareness was higher than the male $(64 \%$ VS $54 \%$ ) of female and male respectively. Yet, still averaged $36 \%$ of both genders do not know. Our findings similar to the Turkish study with $61 \%$ said yes that high fibre diet reduces risk of cancer and 33\% do not know [35]. Poor knowledge about fibre and increased risk was observed in a recent report in Hong Kong by centre of health, department of Health [36]. It was stated that only $25 \%$ of the population whom have been asked not identify low fibre 
intake as a risk of $\mathrm{CRC}$, which was far too low compared to our respondents knowledge.

Our finding is reassuring as people aware of the role of fibre in protection and reducing risk of CRC by following a healthy dietary intake that has higher fibre content. This could be due to consumption of more fruits and vegetables or whole grains $[14,37]$. The role of fibre in reducing risk of CRC has been hypothized in many studies. One theory is that at the level of the nuclei healthy diet including high fibre suppress production of tumor inducing substances, hence; decrease the chance of cells proliferating to be cancerous cells [38]. The other hypothesis was that low fibre intake come within a dietary pattern that could be named a western or high meat based diet. Low fibre with refined grains intake combined with high processed meat and fatty food consumption had been shown to increase the risk of cancer to level that was up to 11.7 times higher than none consumers [39].

The poor knowledge might be priory risk factor to develop CRC as previous study in the KSA found that low fruit and vegetables consumption is lower in CRC patients compared to normal control subjects [40]. Hence, poor dietary pattern that have high fat and low fibre could be blamed.

It is well known that family and personal dietary habits has a great impact on the body weight, hence leading to obesity. Poor dietary patterns combined with obesity could be a trigger to increased colon cancer risk. A proposed chemical and pathophysiological mechanism, in short, can explain the relationship. Obesity might increase the risk of CRC through enhancing insulin resistance and hyperinsulinemia. Insulin like growth factor 1 (IGF-1) increased due to obesity, induced hyperinsulinemia, which result from less physical activity and western diet, the IGF-1 goes through chemical pathway leading to increase caner cells growth and proliferation and reduce their death rate $[38,41]$.

Therefore, one of the aims of the current study was to examine the population awareness of the hazardous relationship between obesity and higher risk of CRC. The population awareness of obesity as a risk factor scores low and negative in the current study. It was found that about half of the respondents (both genders) do not belief that obesity related to increased CRC risk, in comparison to only up to $12 \%$ of both groups have a positive belief. This is most disturbing with the huge amount of educational campaigns and programs in KSA with regards to obesity related diseases and risk. In a recent Turkish study in women, their knowledge was better than our respondents where $72 \%$ knew that being overweight increased the risk of CRC [35]. In our study about $40 \%$ do not know if obesity related to CRC increased risk compared to only $24 \%$ lacking the knowledge about this important relationship in Baran study [35].
Yet, our subjects scored better than a Hong Kong survey by $\mathrm{DoH}$, where it found only $1 \%$ can relate obesity or visceral obesity to higher risk of CRC [36].

\section{Conclusions}

In conclusion, most of people did not have any information about early CRC screening test and most of them refused to do any of these tests as they were embarrassed or feeling those tests are dirty.

The current subjects did not know the order of CRC as disease for their gender or to the opposite gender. Both genders did not realize that with presence of risk factors, they will be in higher risk to develop CRC.

The study also found that there is inadequate knowledge about the relationship of poor cooking methods and obesity to $\mathrm{CRC}$ as indictors of dietary behaviors. However, better understanding to the role of fibre in protection against cancer does exist.

The result of the study showed low level of knowledge about CRC among our population that need to be addressed by health authority and to establish national wide programs to increase the awareness about the disease and screen individuals who at risk. In addition, more emphasis on the importance of dietary modification to decrease the prevalence of the disease among our population is a most.

\section{Acknowledgements}

The research team would like to thank Al-Sheik Jameel Khoker Scientific Chair for Colon Diseases and Colorectal Cancers for funding this project and made it possible (funding contract no ICRS211/ 2-2-2011), also we would like to thanks the students for their massive contribution in data collections and to the participants for their time and care. Also, our thanks extended to the supervisor of the chair; Dr. Suleiman Abdulaziz Jastaniah.

Special thanks go to Professor Eslam Header for his massive support and guidance throughout the project and Dr. Firas Al-Eizzah for his valuable contribution to the successes of the research and data analysis.

\section{No Conflict of Interest}

Ethical approval is granted for the project by committee of research ethics in the faculty of applied medical sciences, UQU, KSA

Consents forms have been provided, explained and signed by all respondents to show that all data will be kept confidentially in locked files cabinet and in laptops with pass words, no harm to be come to them and they can withdraw at any time. If data become public, no cross-reference to the volunteers names or personal information will be shown and indentify them 
This opposite and mistaken understanding in our population might be due to that no emphasis on the relationship of obesity to cancer does exist. However, the focus of the campaigns could be on diabetes and CVD and obesity.

Table 2. Socio-demographic factors (age, educational levels and total income) divided by gender groups

\begin{tabular}{|c|c|c|c|c|c|c|c|}
\hline \multirow{2}{*}{ Socio-demographic factors } & \multirow{2}{*}{ Categories for variables } & \multicolumn{2}{|c|}{ Male } & \multicolumn{2}{|c|}{ Female } & \multicolumn{2}{|c|}{ Total } \\
\hline & & No. & $\%$ & No. & $\%$ & No. & $\%$ \\
\hline \multirow{6}{*}{ Age } & $<20$ & 128 & 9.0 & 178 & 15.8 & 306 & 12.0 \\
\hline & $20-30$ & 885 & 62.2 & 651 & 57.9 & 1536 & 60.3 \\
\hline & $31-40$ & 246 & 17.3 & 171 & 15.2 & 417 & 16.4 \\
\hline & $41-74$ & 164 & 11.5 & 115 & 10.2 & 289 & 11.3 \\
\hline & Total & 1423 & 100.0 & 1125 & 100.0 & 2548 & 100.0 \\
\hline & Literate & 4 & 0.3 & 30 & 2.7 & 34 & 1.4 \\
\hline \multirow{7}{*}{ Education levels } & Primary & 55 & 3.9 & 32 & 2.9 & 87 & 3.5 \\
\hline & Intermediate & 96 & 6.8 & 75 & 6.8 & 171 & 6.8 \\
\hline & Secondary & 469 & 33.4 & 197 & 17.8 & 666 & 26.5 \\
\hline & Graduate & 744 & 52.9 & 738 & 66.6 & 1482 & 58.9 \\
\hline & Postgraduate & 38 & 2.7 & 36 & 3.2 & 74 & 2.9 \\
\hline & Total & 1406 & 100.0 & 1108 & 100.0 & 2514 & 100.0 \\
\hline & $<1500$ & 368 & 26.9 & 244 & 25.0 & 612 & 26.1 \\
\hline \multirow{6}{*}{ Total income (SR*) } & $1500-<3500$ & 204 & 14.9 & 202 & 20.7 & 406 & 17.3 \\
\hline & $3500-<5000$ & 174 & 12.7 & 92 & 9.4 & 266 & 11.3 \\
\hline & $5000-<7000$ & 126 & 9.2 & 100 & 10.2 & 226 & 9.6 \\
\hline & $7000-<10000$ & 217 & 15.9 & 134 & 13.7 & 351 & 15.0 \\
\hline & up to 10000 & 280 & 20.5 & 204 & 20.9 & 484 & 20.6 \\
\hline & Total & 1369 & 100.0 & 976 & 100.0 & 2345 & 100.0 \\
\hline
\end{tabular}

* SR: Saudi Riyal

Table 3. Respondents knowledge of CRC prevalence worldwide and according to country development level divided by genders.

\begin{tabular}{|c|c|c|c|c|c|c|c|c|}
\hline \multirow{2}{*}{ Gender } & \multicolumn{2}{|c|}{ Male } & \multicolumn{2}{|c|}{ Female } & \multicolumn{2}{|c|}{ Total } & \multirow{2}{*}{$X^{2}$} & \multirow{2}{*}{ Sig } \\
\hline & No. & $\%$ & No. & $\%$ & No. & $\%$ & & \\
\hline \multicolumn{9}{|c|}{ Colorectal cancer is widespread in the world } \\
\hline No & 158 & 11.2 & 98 & 9.0 & 256 & 10.2 & \multirow{4}{*}{8.6} & \multirow{4}{*}{0.014} \\
\hline Yes & 367 & 26.0 & 248 & 22.7 & 615 & 24.6 & & \\
\hline I do not know & 887 & 62.8 & 747 & 68.3 & 1634 & 65.2 & & \\
\hline \multirow[t]{2}{*}{ Total } & 1412 & 100.0 & 1093 & 100.0 & 2505 & 100.0 & & \\
\hline & \multicolumn{7}{|c|}{ The belief that CRC is higher in western countries than developing countries. } & \\
\hline No & 107 & 7.6 & 82 & 7.6 & 189 & 7.6 & \multirow{3}{*}{1.60} & \multirow{3}{*}{0.661} \\
\hline Yes & 307 & 21.9 & 228 & 21.0 & 535 & 21.5 & & \\
\hline I do not know & 987 & 70.4 & 775 & 71.4 & 1762 & 70.8 & & \\
\hline Total & 1401 & 100.0 & 1085 & 100.0 & 2486 & 100 & & \\
\hline
\end{tabular}

Table 4. Respondents knowledge of position of CRC risk and the most affected gender in Saudi Arabia divided by genders.

\begin{tabular}{llllll} 
Gender & Male & Female & Total & $X^{2}$ & Sig \\
\hline
\end{tabular}




\begin{tabular}{|c|c|c|c|c|c|c|c|c|}
\hline & No. & $\%$ & No. & $\%$ & No. & $\%$ & & \\
\hline \multicolumn{9}{|c|}{ Arrangement of colorectal cancer in Saudi Arabia } \\
\hline First & 70 & 5.0 & 19 & 1.8 & 89 & 3.6 & & \\
\hline Second & 136 & 9.7 & 79 & 7.3 & 215 & 8.7 & & \\
\hline Third & 167 & 11.9 & 140 & 13.0 & 307 & 12.4 & 23.56 & 0.001 \\
\hline Do not know & 1032 & 73.5 & 837 & 77.9 & 1869 & 75.4 & & \\
\hline Total & 1405 & 100.0 & 1075 & 100.0 & 2480 & 100.0 & & \\
\hline \multicolumn{9}{|c|}{ Are men usually more affected by colorectal cancer than women? } \\
\hline Yes & 320 & 22.7 & 200 & 18.3 & 520 & 20.8 & & \\
\hline No & 110 & 7.8 & 129 & 11.8 & 239 & 9.6 & 16.07 & 0.001 \\
\hline Do not know & 977 & 69.4 & 763 & 69.9 & 1740 & 69.6 & & \\
\hline Total & 1407 & 100.0 & 1092 & 100.0 & 2499 & 100.0 & & \\
\hline
\end{tabular}

Table 5. The recognition of early screening test for CRC (the FOBT)and the barriers to perform it divided by genders.

\begin{tabular}{|c|c|c|c|c|c|c|}
\hline \multirow{2}{*}{ Gender } & \multicolumn{2}{|c|}{ Male } & \multicolumn{2}{|c|}{ Female } & \multirow{2}{*}{$\mathbf{X}^{2}$} & \multirow{2}{*}{ Sig } \\
\hline & No. & $\%$ & No. & $\%$ & & \\
\hline \multicolumn{7}{|c|}{ Do people know what the common early screening test is for CRC? } \\
\hline Blood in the stool FOBT & 167 & 12.1 & 174 & 16.6 & \multirow{4}{*}{16.84} & \multirow{4}{*}{0.001} \\
\hline Examination of blood serum & 67 & 4.9 & 27 & 2.6 & & \\
\hline I do not know & 1143 & 83.0 & 848 & 80.8 & & \\
\hline Total & 1377 & 100.0 & 1049 & 100.0 & & \\
\hline \multicolumn{7}{|c|}{ Worried that FOBT may be inconvenient } \\
\hline Yes & 39 & 2.8 & 34 & 3.2 & \multirow{3}{*}{4.84} & \multirow{3}{*}{0.08} \\
\hline No & 1354 & 97.2 & 1035 & 96.8 & & \\
\hline Total & 1393 & 100.0 & 1069 & 100.0 & & \\
\hline \multicolumn{7}{|c|}{ How much people worried about the messiness and dirtiness of FOBT } \\
\hline Don't Know FOBT & 627 & 44.7 & 352 & 32.9 & \multirow{5}{*}{68.01} & \multirow{5}{*}{0.001} \\
\hline Not at All Worried & 166 & 11.8 & 111 & 10.4 & & \\
\hline Not Very Worried & 240 & 17.1 & 159 & 14.9 & & \\
\hline Somewhat Worried & 227 & 16.2 & 276 & 25.8 & & \\
\hline Extremely Worried & 144 & 10.3 & 172 & 16.1 & & \\
\hline Total & 1404 & 100.0 & 1070 & 100.0 & & \\
\hline
\end{tabular}

Table 6. the knowledge about cooking types, high fiber diet and obesity divided by genders

\begin{tabular}{|c|c|c|c|c|c|c|}
\hline Gender & No. & $\%$ & No. & $\%$ & & \\
\hline & the $\mathrm{cc}$ & in relat & se risk & & & \\
\hline Yes & 146 & 10.4 & 110 & 10.1 & \multirow{4}{*}{18.28} & \multirow{4}{*}{0.001} \\
\hline No & 718 & 51.2 & 649 & 59.4 & & \\
\hline I do not know & 538 & 38.4 & 334 & 30.6 & & \\
\hline Total & 1402 & 100.0 & 1093 & 100.0 & & \\
\hline \multicolumn{7}{|c|}{ the high fiber diet(fruits, vegetables and grains) in relation to increase risk of CRC } \\
\hline Yes & 759 & 54.1 & 688 & 63.6 & \multirow{4}{*}{24.76} & \multirow{4}{*}{0.001} \\
\hline No & 74 & 5.3 & 34 & 3.1 & & \\
\hline I do not know & 569 & 40.6 & 359 & 33.2 & & \\
\hline Total & 1402 & 100.0 & 1081 & 100.0 & & \\
\hline \multicolumn{7}{|c|}{ Obesity in relation to increase risk of $\mathrm{CRC}$} \\
\hline Yes & 146 & 10.3 & 142 & 13.0 & \multirow{4}{*}{9.31} & \multirow{4}{*}{0.01} \\
\hline No & 654 & 46.4 & 539 & 49.2 & & \\
\hline I do not know & 611 & 43.3 & 414 & 37.8 & & \\
\hline Total & 1411 & 100.0 & 1095 & 100.0 & & \\
\hline
\end{tabular}




\section{REFERENCES}

[1] Ferlay J, Soerjomataram I, Ervik M, Dikshit R, Eser S, Mathers C, Rebelo M, Parkin DM, Forman D, Bray, F.GLOBOCAN 2012 v1.0, Cancer Incidence and Mortality Worldwide: IARC Cancer Base No. 11 [Internet]. Lyon, France: International Agency for Research on Cancer.

[2] WHO (World Health Organization), 2014. Cancer, Media Center. Available from: http://www.who.int/mediacentre/factsheets/fs297/en/. [Accessed on: February 2014].

[3] Arnold M, SierraM S, Laversanne M, SoerjomataramI, JemalA, and Bray F. Global patterns and trends in colorectal cancer incidence and mortality, GUT, 2015, 310912

[4] Goodbrand, S. A. and Steele, R. J. C. An overview of colorectal cancer screening. Scottish Medical Journal, 2008 53(4), p. 31-37.

[5] Innes, K., Wimsatt J., Frisbee S. And Ducatman, A. (2014). Inverse association of colorectal cancer prevalence to serum levels of perfluorooctanesulfonate (PFOS) and perfluorooctanoate (PFOA) in a large Appalachian population. BMC Cancer, 14:45.

[6] Al-Ahwal, M., Shafik, Y. and Al-Ahwal, H. (2013). First national survival data for colorectal cancer among Saudis between 1994 and 2004: what's next?. BMC Public Health, 13:73-79.

[7] Al-Eid, H. (2009). Cancer Incidence Report, Saudi Arabia 2009.Saudi Cancer Registry, Ministry of Health, Kingdom of Saudi Arabia. Available at: http://www.scr.org.sa/. [Accessed on: March 2010].

[8] SayedAlamin Z, Al-Andijani A, Al-NawwamLamfon M, Atta MM (2016). Assessment of the knowledge and awareness of CRC among undergraduate students in SA; a survey based study American Journal of Research Communications Vol (4) issue (3), 2016

[9] Smith RA, von Eschenbach AC, Wender R, et al. (2001). American Cancer Society guidelines for the early detection of cancer: update of early detection guidelines for prostate, colorectal, and endometrial cancers. Also: update 2001 - testing for early lung cancer detection. CA Cancer J Clin; 51:38-75.

[10] CDC (Center for Disease Control and Prevention). (2013). Colorectal cancer screening rates remain low. CDC. Available from:http://www.cdc.gov/media/releases/2013/p 1105-colorectal-cancer-screening.html.[Accessed on: November 5, 2013].

[11] Harmy, MY, Norwati D, et al. (2011).knowledge and attitude of colorectal cancer screening among moderate risk patients in west Malaysia, asian pacific. Cancer Prevention, 12: 1957-1960.

[12] Taskila, T., Wilson, S., et al. (2009). "Factors affecting attitude toward colorectal cancer screening in the primary care population. British Jr Cancer, 101(2): 250-255.
[13] Vargas A J and Thompson P A (2012), Diet and Nutrient Factors in Colorectal Cancer Risk, NutrClinPract October 2012 vol. 27 no. 5 613-623.

[14] Institute Of American Cancer Research and World Cancer Research Fund (IACR and WCRF, 2011). Colorectal cancer reports in food, nutrition, physical activity and the prevention of cancers, Washington DC.

[15] Lewine H, 2015, Harvard health publications, Harvard reviews of health news, April 2015.

[16] Baena R and Salinas P (2015) diet and CRC, Maturitas, 80(3)pp. 258-264

[17] Zubaidi AM, AlSubaie NM, AlHumaid AA, Shaik SA, AlKhayal KA, AlObeed OA (2015), Public awareness of colorectal cancer in Saudi Arabia: A survey of 1070 participants in Riyadh. Saudi J Gastroenterol.21(2):78-83

[18] Imran M, Sayedalamin Z, Alsulami SS, Atta M, Baig M. Knowledge and Awareness of Colorectal Cancer among Undergraduate Students at King Abdulaziz University, Jeddah, Saudi Arabia: a Survey-Based Study. Asian Pac J Cancer Prev. 2016,17(5):2479-83.

[19] Wolf M. S., Rademaker A, Bennett C L., Ferreira R, Dolan N C., Davis T C, Medio F, Liu D, Lee J, Fitzgibbon M, Development of a Brief Survey on Colon Cancer Screening Knowledge and Attitudes Among Veterans, Preventive Chronic Diseases 2005, VOLUME 2: NO. 2, pp1-10.

[20] Robb K, Stubbings S, Ramirez A, Macleod U, Austoker J, Waller J, Hiom S and Wardle J (2009) Public awareness of cancer in Britain: a population-based survey of adults, British Journal of Cancer, 101, S18-S23

[21] Power E, Simon A, Juszczyk D, Hiom S and Wardle J (2011). Assessing awareness of colorectal cancer symptoms: Measure development and results from a population survey in the UK, BMC Cancer, 11:366

[22] Ravichandran K, Mohamed G, et al. (2010). "Public knowledge on cancer and its determinants among Saudis in the Riyadh Region of Saudi Arabia. Cancer Prevention, 11(5): 1175-1180.

[23] Parvez T, Gumgumji AA, Anwar MS, and Al-Ahmadi SS. (2004).Awareness about causes of gastrointestinal tract (GIT) malignancies. J Coll Physicians Surg Pak. 14(2):98-101.

[24] Al Naggar RA, Al-Kubaisy W, Yap P A, Bobryshv Y V, Osman MT (2015) Attitudes towards CRC and CRC screening terst among elderly Malay patients, Asian Pac. J. Cancer Prev, 16(2), 67-674.

[25] Ghahramani S, Jahani P, Abdullahifard G(2015) comparison of knowledge and attitude. International Journal of school health, 2(2) pp 1-55

[26] American Cancer Society. Access 28/2/2016

[27] Murdani A, Achmad, F Ari D. et al. (2009). Hospital-based survey on knowledge and attitude toward colorectal cancer screening among Indonesian population. Endoscopy: 10:51-55.

[28] Dolan NC, Ferreira MR, Davis TC, et al (2004). Colorectal cancer screening knowledge, attitudes, and beliefs among 
veterans: Does literacy make a difference? J ClinOncolo, $22,2617-22$.

[29] Fedewa SA, Cullati S, Bouchardy C, Welle I, Burton-Jeangros C, Manor O, et al. (2015) Colorectal Cancer Screening in Switzerland: Cross-Sectional Trends (2007-2012) in Socioeconomic Disparities. PLoS ONE 10(7): e0131205.

[30] Sinha R, Peters U, Cross AJ, Kulldorff M, Weissfeld JL, et al (2005): Meat, Meat cooking methods and preservation and risk for colorectal adenoma, Cancer research, 65: 17pp 8034-41

[31] Tuan J and Chen YX (2016): Dietary and lifestyle factors associated with colorectal cancer risk and interactions with Microbia: fibre, red or processed meant and alcoholic drinks, Gastrointest Tumors, 3pp 17-24

[32] Gerhardsson de Verdier M, Hagman U, Peters RK, Steineck G, Overvik E. 1991, Meat, cooking methods and colorectal cancer: a case-referent study in Stockholm. Int J Cancer. 21; 49(4):520-5.

[33] Dobarganes G and Marques-Ruiz G (2015), Possible adverse effects of frying with vegetable oils. British Journal of Nutrition (2015), 113, S49-S57

[34] Giuliani A. Ferrara F. Scimo` M. Angelico F. Olivieri L. Basso L. (2014), Adipose tissue fatty acid composition and colon cancer: a case-control study. Eur J Nutr (2014) 53:1029-1037

[35] Baran G K, Pınar G, Şahin S. (2016), Determination of risk factors, Knowledge level and awareness on colorectal cancers among Turkish women. Behav Health Vol 5(3)pp 109-116

[36] Department of health, non-communicable diseases watch: about CRC and screening, September, 2016, Hong Kong, from website www.colonscreen.gov.hg

[37] Katalambula L K, Ntwenya J E, Ngoma T, Buza J, Mpolya E, Paul E and Petrucka P (2017), Dietary pattern as a predictor of colorectal cancer among general health population in Arusha Tanzania: A population based descriptive study International Journal of Nutrition and Metabolism Vol. 9(3), pp. 20-29

[38] Kasdagly M, Radhakrishnan S, Reddivari L, Veeramachaneni DN, Vanamala J (2014). Colon carcinogenesis: influence of Western diet-induced obesity and targeting stem cells using dietary bioactive compounds. Nutrition.,30(11-12)pp 1242-56

[39] Randi G, Edefonti V, Ferraroni M, La Vecchia C, Decarli A. (2010), Dietary patterns and the risk of colorectal cancer and adenomas. Nutrition Review. 2010 Jul;68(7):pp389-408

[40] Alamri F A., Saeedi M Y., Kassim A. K (2014), Dietary and other risk factors for Colo-Rectal cancer in Saudi Arabia Journal of Medicine and Medical Sciences Vol. 5(10) pp. 222-229

[41] Godos J., Bella F., Torrisi A., Sciacca S., Galvano F., Grosso G. (2016) Dietary patterns and risk of colorectal adenoma: a systematic review and meta-analysis of observational studies. J Hum Nutr Diet. 29, 757-76. 